Rev. Bras. Saúde Prod. Anim., Salvador, v.13, n.2, p.558-568 abr./jun., 2012 http://www.rbspa.ufba.br ISSN 15199940

\title{
Zootecnia de precisão: princípios básicos e atualidades na suinocultura ${ }^{1}$
}

\author{
Precision animal production: basic principles and news in the swine production
}

\author{
PANDORFI, Héliton²*; ALMEIDA, Gledson Luiz Pontes²; GUISELINI, Cristiane ${ }^{2}$
}

\footnotetext{
${ }^{1}$ Revisão apresentada no Congresso Brasileiro de Zootecnia (ZOOTEC 2011).

${ }^{2}$ Universidade Federal Rural de Pernambuco, Departamento de Tecnologia Rural, Recife, Pernambuco, Brasil.

*Endereço para correspondência: pandorfi@dtr.ufrpe.br
}

\section{RESUMO}

Este trabalho foi conduzido com o objetivo de apontar a inserção da Zootecnia de Precisão no atual modelo de produção de suínos, bem como sua potencialidade no aprimoramento do sistema produtivo, baseado nos princípios da engenharia de processos, assim como nos parâmetros fisiológicos, físicos e biológicos dos animais. Foram abordados no texto os princípios tecnológicos fundamentais à tecnologia de precisão e os principais desafios que se colocam ao seu desenvolvimento, bem como a apresentação de vários exemplos concretos da sua prática internacional e no próprio país. Espera-se assim, por meio da divulgação de sistemas interativos e dinâmicos, citar algumas aplicações, tais como a identificação animal, os aspectos comportamentais, o ambiente físico das instalações dos animais e as emissões de gases poluentes, com ênfase no aprimoramento dos índices zootécnicos que respeitem as regras de bem-estar animal.

Palavras-chave: automação, bem-estar animal, sistemas inteligentes

\section{SUMMARY}

This study was conducted with the objective of identifying the insertion of Precision Animal Production in the current pig production model and its potential to the improvement of the production system, based on engineering principles processes, as well as animals physiological, physical and biological parameters in the text the technological principles that serve as basis for precision technology and the key challenges facing the development as well as presenting several concrete examples of its international practice and in the country were addressed. It is expected, through the dissemination of interactive and dynamic systems, to cite some applications, such as animal identification, behavioral aspects, physical environment animal facilities and emissions of gases, with emphasis on improvement in performance indexes within the rules of animal welfare.

Keywords: animal welfare, automation, intelligent system

\section{INTRODUÇÃO}

A modernização da suinocultura exige esforços multidisciplinares para alcançar bons índices zootécnicos e, em consequiência, resultados econômicos satisfatórios. Essa tendência persiste para os próximos anos, sustentada pelos investimentos em reformas de instalações no campo, pelas ampliações industriais e pela construção de novas granjas e modernas fábricas. Também deram suporte à expansão da produção, os investimentos na garantia da sanidade, na redução do impacto ambiental, na segurança dos alimentos e no bem-estar animal.

Frente às atuais demandas, não se pode mais considerar sistema de produção animal, cadeia produtiva, 
padrões comportamentais, sem destacar o conceito de bem-estar na produção.

Diante disso, o uso da tecnologia da informação, microeletrônica, técnicas de modelagem, monitoramento por imagens, sensores e atuadores, podem melhorar o trabalho científico-tecnológico, de modo a favorecer a acurácia das pesquisas e o desenvolvimento de sistemas especialistas para tomada de decisão.

$\mathrm{O}$ futuro do comércio de proteína animal depende, principalmente, de como a indústria conduzirá os seguintes princípios: honestidade, disponibilidade de informações, rastreabilidade, segurança/qualidade e flexibilidade para mudanças. Indo de encontro a tudo isto, surge um novo conceito na produção de alimentos: "Produção Animal de Precisão" ou "Zootecnia de Precisão".

A efetiva contribuição da "Zootecnia de Precisão" é fornecer meios ao produtor de monitorar seus empreendimentos de forma prática, e alcançar índices produtivos com base em informações geradas por sistemas especialistas. No entanto, para que isso ocorra, é necessário o emprego de ferramentas tecnológicas que diminuam as perdas e possibilitem o controle mais rígido do sistema produtivo, de maneira a tornar a suinocultura industrial brasileira mais competitiva e empreendedora.

Nesse contexto, é necessário lembrar que qualquer proposta relativa ao aprimoramento da suinocultura deve basear-se em resultados de estudos científicos, realizados com animais de produção e que evitem possíveis distorções do mercado externo frente às exportações da carne suína nacional.

Revela-se assim, o interesse em como medir os níveis de estresse dos animais e qual a influência do ambiente nos parâmetros fisiológicos e no acondicionamento ambiental, com o objetivo de integrar informações registradas nos animais e os desvios as suas necessidades, de modo a atuar, em tempo real, sobre o manejo dos animais e o controle do microclima no interior das instalações.

\section{O AMBIENTE DE PRODUÇÃO NA SUINOCULTURA}

Os componentes ambientais podem ser divididos em físicos (temperatura, umidade, ventilação, tipologia das instalações), sociais (hierarquia, tamanho e composição do grupo, presença ou ausência de animais estranhos) e o manejo (dieta, formas de arraçoamento, desmame). $\mathrm{O}$ ambiente físico, por abranger os elementos meteorológicos que afetam os mecanismos de transferência de energia, a regulação e o balanço térmico entre o animal e o meio, exerce forte influência sobre $\mathrm{o}$ desempenho e a saúde dos animais (SAMPAIO et al., 2004).

O conforto e o bem-estar animal sofrem diretamente com a interferência do ambiente na criação intensiva, o que ocasiona dificuldade na manutenção do balanço térmico no interior das instalações, na expressão de comportamentos naturais e afeta $o$ desempenho produtivo e reprodutivo dos suínos (PANDORFI et al., 2007).

O suíno é considerado agente modificador do meio onde vive, seja pela geração de calor, vapor d'água, fezes, urina, seja como foco de desenvolvimento de patógenos. Nessas condições, o verdadeiro ambiente passa a ser aquele reinante no interior da edificação ou aquele cujo ar os animais respiram.

A insalubridade nas instalações é pouco considerada no meio rural. Tomam ainda maiores proporções na suinocultura, atividades nas quais o animal se encontra em um ambiente 
com altos níveis de ruído, vapor d'água, gases (amônia, gás carbônico, gás sulfídrico) e poeira que, muitas vezes, ultrapassam limites exigidos para a manutenção do bem-estar e da saúde.

É necessário, portanto, um controle da qualidade do ar, nas instalações para suínos que, provavelmente, poderão melhorar os níveis de produtividade, ao expor os animais a menores riscos de saúde. Quanto à concentração de gases, principalmente quando se trata da amônia, é necessária mensuração mais frequente.

Algumas pesquisas almejam viabilizar a utilização de equipamentos de mensuração de gases para minimizar os custos de aquisição e a manutenção dos equipamentos (CAMPOS et al., 2009; SAMPAIO et al., 2004). Ao controlar a qualidade de ar, pelo manejo de ventilação e nebulização, é possível manter o ambiente dentro dos níveis aceitáveis apontados pela legislação brasileira (SAMPAIO et al., 2005).

\section{ZOOTECNIA DE PRECISÃO APLICADA}

Denomina-se "Suinocultura de Precisão" parte da suinocultura, que emprega o uso da tecnologia da informação, sensores e atuadores para o registro de informações relacionadas ao sistema de produção e às interferências das variáveis ambientais nas unidades produtivas. Esta visa a reduzir ou evitar perdas localizadas, o que propicia um controle preciso sobre a utilização dos recursos envolvidos na cadeia produtiva. As tecnologias trazem soluções simples e eficientes para grandes problemas, relacionados com o ambiente, manejo de equipamentos e controle de rebanhos na produção industrial de suínos (PANDORFI et al., 2005a).

Uma das maiores limitações é a ausência de recursos de automação para o registro de dados no campo, o que implica muitos riscos para a rentabilidade e para a sustentabilidade no setor primário. A automação dos processos é muito importante, pois permite visualizar o sistema de produção por uma ótica mais ampla, o monitoramento das atividades, eficiente análise de dados e geração de informações que sejam favoráveis a decisões mais seguras e inteligentes. Dessa forma, todas as áreas envolvidas podem ser proativas em suas responsabilidades e o tempo e recursos melhor aproveitados (PANDORFI et al., 2006).

\section{IDENTIFICAÇÃO ELETRÔNICA}

Nas últimas décadas, o aumento da produção de suínos, pressionada por uma crescente procura de alimentos, tem-se caracterizado por um aumento no tamanho e na concentração de animais nas unidades de produção, a dificultar o registro dos dados de cada animal em particular. Os sistemas automáticos de identificação eletrônica podem auxiliar na detecção de doenças, resposta fisiológica ao estresse ambiental, ingestão de alimentos, atividade física e o impacto ambiental causado pelo sistema de produção, de maneira a promover melhor controle na propriedade. Transponders injetáveis e brincos eletrônicos têm sido utilizados no processo de identificação eletrônica (SILVA \& NÄÄS, 2006; PANDORFI, et al., 2005b; CARO et al., 2003).

A União Europeia preconiza a identificação de todos os animais (bovinos, suínos, caprinos e ovinos) 
para total controle do nascimento à linha de abate e define um padrão mundial para os dispositivos eletrônicos de identificação para assegurar a compatibilidade entre os sistemas dos diferentes fabricantes. Possibilita ainda, dessa maneira, a ampla projeção do registro e identificação de todos os animais e contribui para o desenvolvimento de um modelo de rastreabilidade na cadeia suinícola (WISMANS, 1999).

Seja qual for o dispositivo, um identificador eletrônico possui um transmissor que emite um número de série, o qual permite identificar o animal e monitorar a sua atividade. É possível distinguir os princípios de funcionamento dos diferentes sistemas portadores de informação e reconhecimento, aplicados à identificação (CARO et al., 2003).

$\mathrm{O}$ uso de transmissores pode ser mais interessante no caso de animais de reprodução, que permanecem mais tempo na propriedade. Além do controle do consumo de ração, o sistema também pode ser usado para registrar as cobrições, vacinações, nascimentos, desmames etc. Com registros adequados, as cobrições mais recomendáveis podem ser especificadas, em função do grau de parentesco dos animais e da data de utilização do macho. Informações semelhantes podem ser utilizadas para inseminação artificial (SILVA \& NÄ̈̈S, 2006).

Uma fazenda experimental da Universidade do Estado de Iowa combinou um sistema de alimentação com a identificação eletrônica de porcas prenhes, em um rebanho não confinado, o que permitiu à porca exercitar-se durante o período de gestação e conviver em grupos sociais. Ressalte-se que se manteve, nesse experimento, o controle do fornecimento de ração e ganho diário de peso, quando comparados a duas formulações distintas. O sistema de alimentação eletrônico torna-se de grande eficiência, quando os animais são alojados em grupos, pois a exemplo do experimento citado, permitem controlar a necessidade nutricional de cada porca e evitar comportamentos agressivos dentro do rebanho, o que garante a vigilância do peso e a máxima produtividade, cuja consequência se reflete no aumento da longevidade do rebanho (HOFF, 1998).

A identificação, isoladamente, não apresenta nenhum significado, pois deve vir seguida de um sistema de aquisição e armazenamento de dados que proporcione acesso fácil às informações, não somente aos produtores, mas também ao consumidor final, para garantir a rastreabilidade da produção.

A evolução em termos de novos equipamentos e pessoal especializado deverá suprir as carências nesses aspectos e, futuramente, haverá a possibilidade de acesso livre aos dados de interesse em termos de produção animal. A adoção de um sistema de rastreabilidade suinícola no Brasil é inevitável. Isso contribuirá para estabelecer e assegurar uma posição de destaque em termos de exportação, bem como para o controle sanitário eficiente e a criação de um padrão internacional de qualidade da carne suína.

\section{SISTEMAS INTELIGENTES INTEGRADOS}

A agricultura e a pecuária têm passado por inúmeras transformações, o que torna a atividade cada vez mais competitiva e, por sua vez, exige do produtor maior nível de especialização, capacidade de gerenciamento e profissionalismo. Os produtores, além de administradores, cada vez mais terão de assumir a função de produtores pesquisadores de suas áreas, posição que os levará a atuar diretamente no registro de dados e geração de 
protocolos integrados à informação, associado a novas técnicas de manejo como auxílio à tomada de decisão. A viabilização da zootecnia, com a obtenção de lucro satisfatório, está sempre em risco, visto a existência de fatores controláveis e incontroláveis que definem a produção suinícola.

O modelo conceitual de monitoramento integrado ligado à produção e ao bemestar dos animais foi proposto por (FROST et al., 1997), como pode ser observado na Figura 1. Nota-se que toda a automação dos sistemas inteligentes deve ter respaldo de alto nível de conhecimento e das etapas do processo produtivo para compor, assim, a interpretação das rotinas que fornecerão base ao banco de dados e aos modelos matemáticos regentes do equacionamento dos diferentes pontos de estrangulamento da produção. A automação dos sistemas visa também à entrada de informações e à saída de comandos por meio dos sensores registradores, o que facilita todo $\mathrm{o}$ trabalho.

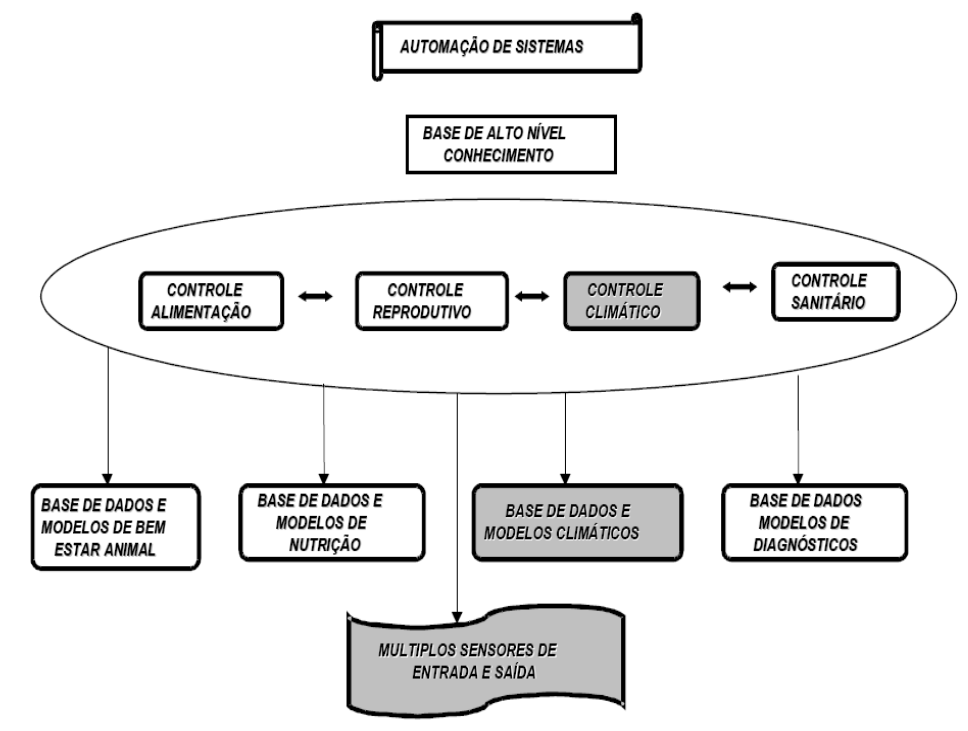

Figura 1. Conceito de sistemas de monitoramento integrado para produção animal

Sistemas de automação têm grande potencial de uso na agropecuária, utilizados na agricultura e zootecnia de precisão, para automatizar processos, monitorar com eficácia os sistemas, otimizar a produção e reduzir perdas. Um sistema bem elaborado pode responder a situações de adversidade de forma inteligente, com a incorporação de ferramentas computacionais, tais como lógica fuzzy e redes neurais artificiais, que propiciam o melhor entendimento de determinada problemática de forma excelente.
A teoria fuzzy se baseia no princípio de que o pensamento humano é estruturado não em números, mas sim em classes de objetos, cuja transição entre pertencer ou não a um conjunto é gradual e não abrupta. A utilização da lógica fuzzy é especialmente adequada a problemas de natureza biológica, pois estes apresentam as seguintes características: o processo é definido de maneira vaga, imprecisa, incerta; há ocorrência de situações de difícil estimação ou avaliação dos parâmetros que definem o processo; o sistema é não linear e variante no tempo; 
há ocorrência de situações nas quais é difícil o registro do valor das variáveis; as medidas podem ser pouco confiáveis.

Além disso, com a utilização de regras fuzzy e variáveis linguísticas, o sistema monitorado passa a desfrutar de um conjunto de possibilidades, a saber: simplificação do modelo do processo; melhor tratamento das imprecisões inerentes aos sensores utilizados; facilidade de especificação das regras de controle, em linguagem próxima à natural; satisfação de múltiplos objetivos de controle; facilidade de incorporação do conhecimento de especialistas humanos.

O uso da teoria dos conjuntos fuzzy permitiu inferir dados ambientais resultantes do setor de gestação, com 24 matrizes primíparas, 12 fêmeas alojadas em baias individuais e $12 \mathrm{em}$ baias coletivas, com os estabelecidos pela literatura, por intermédio de base de regras, para a determinação do conforto térmico ambiental, aplicado à matrizes na fase de gestação (PANDORFI, et al., 2007).

Nesse contexto, os modelos de redes neurais artificiais (RNA), também apresentam grande potencial de aplicação na produção animal, em que se faz necessário uma imensa gama de dados, e possibilita a compreensão das relações entre $o$ ambiente e a exploração agropecuária. Apesar de desenvolver um programa de instruções sequenciais, os modelos de RNA exploram muitas hipóteses, simultaneamente, por meio de redes paralelas compostas de muitos elementos conectados por ligações de variáveis pesos (LEE et al., 1999).

As RNA são especificadas pela topologia de rede, nós característicos e regras de treinamento ou aprendizado. Essas regras especificam um peso inicial e indicam como esses pesos têm que se adaptar durante o uso para melhorar o seu desempenho.
Com o avanço da tecnologia da informação, a utilização de sistemas computacionais para a predição de eventos biológicos, com base em históricos individualizados de produção, ganha cada vez mais importância no gerenciamento agrícola e se destaca como uma importante ferramenta na tomada de decisão.

De acordo com Kominacs et al. (2002), estudos preliminares para predição da produção diária de leite em ovelhas em lactação, por meio do uso de RNAs, permitiram um adequado planejamento do fluxo de produção com base nos parâmetros fisiológicos e ambientais.

Por intermédio do uso das RNA foi possível o desenvolvimento de um sistema automatizado de análise de imagens, que fornecia conforto térmico para suínos e ajustava as condições ambientais a níveis apropriados para melhorar o bem-estar animal e a eficiência produtiva. $\mathrm{O}$ bio-sensor do experimento tratava-se do próprio animal. Em um primeiro momento, o autor examinou a viabilidade de classificar o conforto térmico de leitões por rede neural, a partir de suas imagens posturais. Foi incluída uma pesquisa das imagens de comportamento postural como entrada em uma rede neural de retropropagação, com três camadas, a qual foi treinada para classificar o estado de conforto térmico correspondente, como frio, confortável ou quente (XIN, 1999).

O relato dos parâmetros comportamentais por imagens, como variáveis de entrada a uma rede neural artificial (RNA) para a classificação do estado do conforto térmico para suínos, possibilitou o desenvolvimento de um sistema automatizado, em tempo real, pela análise de imagens, que permitiu a avaliação e o controle contínuo do conforto térmico dos suínos confinados, baseados em seus testes padrões de comportamento (SHAO et al., 1998). 
A viabilidade de utilização de RNA para predição de índices zootécnicos com base nas variáveis, temperatura do ar e frequência respiratória em matrizes suínas em gestação, apresentou bom desempenho nesse tipo de problema e permitiu a representação da condição de conforto térmico e bem-estar animal (PANDORFI et al., 2011).

\section{ANÁLISE DE PADRÕES E SINAIS COMPORTAMENTAIS: MONITORAMENTO POR IMAGEM}

A avaliação tradicional e o controle do ambiente na produção de animais confinados são baseados principalmente na temperatura do ar. Tal aproximação apresenta problemas inerentes, por não se tratar de um método interativo com as necessidades dos animais. A temperatura do ar, exclusivamente, não representa o ambiente de criação como um todo, o que também inclui variáveis como umidade (especial em circunstâncias quentes), radiação (em instalações mal isoladas), tipo e condição do piso (seco e/ou molhado), alterações comportamentais, variações na condição nutricional e de saúde dos animais.

Em verdade, o conjunto dessas variáveis apresenta a verdadeira necessidade ambiental dos animais. Contudo, faz-se necessário o registro de todos os fatores internos e externos para se produzir um índice detalhado de conforto para a avaliação e o controle de sua produção (WOUTERS et al., 1990).

Em ambientes agropecuários controlados, tal como as instalações de produção animal, torna-se indispensável o uso de técnicas de controle das variáveis ambientais. A prévia detecção de condições prejudiciais ou irregulares é muito importante, por envolver produtos de valor elevado e o alto custo no sistema de produção. Essas propriedades são controladas geralmente com algum tipo de equipamento local com supervisão humana (COX, 1988).

Os peritos usam frequentemente a informação visual dos animais para o diagnóstico, mesmo antes de toda a condição de alarme ser detectada por meio de sensores e instrumentos, que auxiliam na análise da resposta das variáveis e as relaciona aos dados de produtividade para a detecção de problemas (XIN, 1999).

Ocorre que, às vezes, um especialista, capaz de diagnosticar corretamente uma condição anormal, pode não estar no local para executar uma análise visual, o que torna interessante fornecer $\mathrm{o}$ acesso remoto à informação visual em tempo real, sempre que este for necessário. As câmeras de vídeo podem facilmente ser usadas para essa finalidade, pois fornecem informações pertinentes ao gerente, proprietário ou a um consultor, para a tomada de decisão.

A viabilidade de se observar, simultaneamente, 80 leitões por meio do uso de microcomputador e de microcâmeras, permitiu $\mathrm{o}$ registro individual e simultâneo dos movimentos efetuados pelos animais, possibilitou a obtenção de dados de comportamento dos animais, bem como proporcionou $\mathrm{o}$ processamento e a interpretação das imagens em tempo real (PANDORFI et al., 2005c). Esse sistema consiste em uma microcâmera, uma placa de captura de imagem instalada em um computador e um programa visual que executa a aquisição, processamento e a classificação das imagens dos animais.

A avaliação e os controles interativos do conforto térmico dos suínos pela análise de imagem superam os problemas inerentes ao método convencional, pois, utilizam-se os próprios animais como bio- 
sensor em resposta aos reflexos do ambiente, por meio da análise comportamental (PANDORFI, et al., 2005c).

Outra ferramenta empregada na zootecnia de precisão são as câmeras termográficas. Aplicada há quase três décadas, a técnica de termografia de infravermelho é útil para detecção de problemas de inércia térmica em construções urbanas, recentemente também em instalações rurais, e consiste no uso de termovisores capazes de interceptar radiação de infravermelho emitida por uma superfície qualquer, convertida em imagens térmicas de distribuição de temperatura da superfície envolvida. Atualmente, foram utilizadas para estudo de distribuição de temperatura de superfície de animais, identificação de eventos fisiológicos, diagnósticos de doenças e avaliações quanto à qualidade de carne (KNIIZZZKOVÁ, 2007; MONTANHOLI et al., 2008; BOUZIDA et al., 2009).

A técnica aliada aos conhecimentos de medidas de propriedades físicas de materiais de construção, microclima local e índices zootécnicos de produção são informações úteis para definição de um índice de eficiência térmica para as construções, que além da readequação do ambiente, permite o estudo da dinâmica de trocas térmicas pelos animais. Nesse sentido, busca correlações entre distribuição da temperatura corporal em condições de estresse e de conforto e, possíveis inferências como temperatura retal e de núcleo corpóreo.

\section{VOCALIZAÇÃO}

Frente a momentos de estresse ou conflito, os suínos são capazes de manifestar diferentes comportamentos individuais para conseguir lidar com tais situações. A vocalização é um sinal que os animais utilizam para se expressar e pode ser percebida e tomada como parâmetro mesmo nas primeiras semanas de suas vidas (WATTS \& STOOKEY, 2000).

A análise da vocalização frente ao comportamento dos suínos pode auxiliar no entendimento da profundidade da dor, estresse e desconforto aos quais os animais possam estar submetidos (PUPPE et al., 2005). As condições de estresse podem ser classificadas como ações de separação, fome ou frustração, o que permitem que os animais expressem vocalizações em alta frequência (MARCHANT-FORDE et al., 2003).

As vocalizações de suínos podem ser indicadores de bem-estar transtornado. $\mathrm{O}$ desenvolvimento de sistema que monitora e registra a quantidade de chamadas de tensão pode ser empregado em ambientes de criação, transporte e abatedouro. Ao usar uma combinação de análise de predição linear que, codifica as redes neurais artificiais indica vocalizações de tensão de suínos em baias com erros de reconhecimento pequenos $(<5 \%)$, pode-se ter um dispositivo eficaz para medidas objetivas de tensão aguda (MANTEUFFEL, et al., 2004).

Ideia semelhante a essa pôde ser utilizada para identificar o chamado de tosse de suínos. A tosse é um dos sintomas mais claros de problemas respiratórios em suínos e pode acometer as vias aéreas e os pulmões. Na tentativa de controlar melhor o ambiente destes, foi desenvolvido um software capaz de traduzir os diferentes tipos de sons capturados por meio de um microfone. $\mathrm{O}$ sistema objetiva identificar uma verdadeira tosse suína causada por um determinado agente infeccioso e diferenciá-la de sons como grunidos, sons de metais e barulhos de fundo para que, com isso, seja possível diagnosticar uma doença infecto-contagiosa de caráter respiratório dentro da criação. 
Diferente disto, Marx et al. (2003), ao induzirem a vocalização em leitões, submetidos à castração com e sem anestésicos, percebeu que os chamados dos animais poderiam ser classificados em três formas: o grunido, o guincho e o grito. Além do que, leitões castrados sem anestesia local produziam o dobro do número de gritos do que aqueles castrados com anestesia local. Concluiuse então que a mudança na "pronúncia" dos leitões refere-se a diferentes graus de dor.

Quando os leitões são separados da matriz, eles vocalizam intensamente, com a diferença de que a taxa de chamados em animais mais jovens é maior em frequência e número, do que a de animais algumas semanas mais velhos. E mesmo quando estes retornam junto à porca, pequenas vocalizações podem ser percebidas, de modo que os mais jovens emitem sons em maior proporção do que os mais velhos (SILVA et al., 2007).

Técnicas modernas de análise de expressão do som permitem obter informações para discriminar, analisar e classificar vocalizações específicas. Estudos relacionados a seres humanos demonstram que o monitoramento do som por infravermelho e microfones é capaz de detectar situações de estresse em pacientes idosos ou acometidos por doenças crônicas. Os resultados são obtidos pela extração do som e subsequente classificação.

O estudo da vocalização é uma ferramenta altamente aplicável à produção intensiva de animais por ser uma técnica não invasiva, sem interferência no comportamento animal, que fornecerá parâmetros mais efetivos para a avaliação do bem-estar animal.

Existem inúmeras possibilidades de inserção de sistemas integrados de monitoramento e controle do microclima nas instalações com base nos dados registrados em tempo real, a partir do próprio animal.

$\mathrm{Na}$ planificação desse sistema deve-se contar com uma equipe multidisciplinar constituída por especialistas em fisiologia animal (biólogos, veterinários, zootecnistas) e engenheiros (agrônomos, eletrônicos, de computação).

Para que a zootecnia de precisão se torne uma realidade e para que funcione de um modo promissor há ainda um longo caminho a percorrer, no qual se destacam os seguintes passos: ampliação dos indicadores de estresse animal; desenvolvimento de sistemas ou técnicas de registro de dados sobre os indicadores sem alteração do comportamento animal; avaliar a viabilidade destes sistemas ou técnicas; validação dos dados obtidos; desenvolvimento de softwares que permita a gestão integrada de todas as informações armazenadas.

O monitoramento das condições ambientais internas e externas as instalações, bem como a resposta dos animais à situações de estresse, permitirá efetuar uma gestão integrada e em tempo real, o que permitirá aos animais atingir bons níveis produtivos respeitando as regras de bem-estar animal.

\section{REFERÊNCIAS}

BOUZIDA, N.; BENDADA, A.; ALDAGUE, X.P. Visualization of body termoregulation by infrared imaging. Journal of Thermal Biology, v.34, n.3, p.120-126, 2009.

CAMPOS, J.A.; TINÔCO, I.F.F.; BAÊTA, F.C.; CECON, P.R.; MAURI, A.L. Qualidade do ar, ambiente térmico e desempenho de suínos criados em creches com dimensões diferentes. Engenharia

Agrícola, v.29, n.3, p.339-347, 2009. 
Rev. Bras. Saúde Prod. Anim., Salvador, v.13, n.2, p.558-568 abr./jun., 2012 http://www.rbspa.ufba.br ISSN 15199940

CARO, I.W.; SILVA, I.J.O.; MOURA, D.J.; SEVEGNANI, K.B.. Eficiência das leitoras fixas utilizadas na identificação eletrônica de animais por rádio-freqüência. Revista Brasileira de Agroinformática, v.5, n.2, p.49-58, 2003.

COX, S.W.R. Farm electronics. Oxford: BSP Professional Books, 1988. $156 \mathrm{p}$.

HOFF, S.J. A quasi ad-libitum eletronic feeding system for gestating sows in loose housing. Computers and Eletronics in Agriculture, v.19, n.3, p.277-288, 1998.

KNÍŽKOVÁ, I.; KUNC, P.; GÜRDİL, G.A.K.; PINAR, Y.; SELVİ, K.Ç. Applications of infrared thermography in animal production. Journal of the Faculty of Agriculture, v.22, n.3, p.329-336, 2007.

KOMINACS, A.P. A preliminary study of the application of artificial neural networks to prediction of milk yield in dairy sheep. Computers and Eletronics in Agriculture, v.35, n.1, p.35-48, 2002.

LEE, A.; ULBRICHT, C.;

DORFFNER, G. Application of artificial neural networks for detection of abnormal fetal heart rate pattern: a comparison with conventional algorithms. Journal of Obstetrics and Gynaecology, v.19, n.5, p.482-485, 1999.

MANTEUFFEL, G.; PUPPE, B.E SCHÖN, P. Vocalization of farm animals as a measure of welfare. Applied Animal Behaviour Science, v.88, n.1-2, p.163-182, 2004.
MARCHANT-FORDE, J.N.; BRADSHAW, H.R.; MARCHANTFORDE, M.R.; BROOM, D. M. A note on the effect of gestation housing environment on approach test measures in gilts. Applied Animal Behaviour Science, v.80, n.4, p.28-296, 2003.

MARX, G.; HORN, T.; THIELEBEIN, J.; KNUBEL, B.; VON BORELL, E. Analysis of pain-related vocalization in young pigs. Journal of Sound and Vibration, v.266, n.3, p.687-698, 2003.

MONTANHOLI, Y.R.; ODONGO, N.E.; WANSON, K.C.; SCHENKEL, F.S.; MCBRIDE, B.W.; MILLER, S.P. Application of infrared thermography as an indicator of heat and methane production and its use in the study of skin temperature in response to physiological events in dairy cattle (Bos taurus). Journal of Thermal Biology, v.33, n.2, p.468-475, 2008.

PANDORFI, H.; SILVA, I.J.O.; MOURA, D.J.; SEVEGNANI, B. Microclima de abrigos escamoteadores para leitões submetidos a diferentes sistemas de aquecimento no período de inverno. Revista Brasileira de Engenharia Agrícola e Ambiental, v.9, n.1, p.99-106, 2005a.

PANDORFI, H.; SILVA, I.J.O.; SEVEGNANI, K.B.; CARO, I.W. Locais de implante de microchips de identificação eletrônica de leitões: seleção e validação por meio da análise de imagem. Engenharia Agrícola, v.25, n.1, p.1-9, 2005 b.

PANDORFI, H.; SILVA, I.J.O.

Evaluation of the behavior of piglets in different heating systems using analysis of image and electronic identification.

Agricultural Engineering

International, v.7, n.8, p.1-24, 2005 c. 
Rev. Bras. Saúde Prod. Anim., Salvador, v.13, n.2, p.558-568 abr./jun., 2012 http://www.rbspa.ufba.br ISSN 15199940

PANDORFI, H.; SILVA, I.J.O.; CARVALHO, J.L.; PIEDADE, S.M. Estudo do comportamento cioclimático de matrizes suínas alojadas em baias individuais e coletivas, com ênfase no bem-estar animal na fase de gestação. Engenharia Rural, v.17, n.1, p.1-10, 2006.

PANDORFI, H.; SILVA, I.J.O.; GUISELINI, C.; PIEDADE, S.M.S. Uso da lógica fuzzy na caracterização do ambiente produtivo para matrizes gestantes. Engenharia Agrícola, v.27, n.1, p.83-92, 2007.

PANDORFI, H.; SILVA, I.J.O.; RODRIGUES, V.C.; VIEIRA, F.M.C.; NASCIMENTO, S.T.; GUISELINI, C. Uso de redes neurais artificiais para predição de índices zootécnicos nas fases de gestação e maternidade na suinocultura. Revista Brasileira de Zootecnia, v.40, p.676-681, 2011.

PUPPE, B.; SCHÖN, P.C.; TUCHSCHERER, A.; MANTEUFFEL, G. Castration-induced vocalisation in domestic piglets, Sus scrofa: Complex and specific alterations of the vocal quality. Applied Animal Behaviour Science, v.95, p.67-78, 2005.

SAMPAIO, C.A.P.; CRISTIANI, C.; DUBIELA, J.A.; BOFF, C.E.; OLIVEIRA, M.A. Avaliação do ambiente térmico em instalação para crescimento e terminação de suínos utilizando os índices de conforto térmico nas condições tropicais. Ciência Rural, v.34, n.3, p.785-790, 2004.

SAMPAIO, C.A.P.; NÄÄS, I.A.; NADER, A. Gases e ruídos em edificações para suínos: aplicação das normas NR-15, CIGR e ACGIH.

Engenharia Agrícola, v.25, n.1, p.1018, 2005.
SHAO, J.; XIN, H.; HARMON, J.D.

Comparison of image feature extraction for classification of swine thermal comfort behavior. Computer and Electronics in Agriculture, v.19, n.2, p.223-232, 1998.

SILVA, K.O.; NÄÄS, I.A. Avaliação do uso de identificadores eletrônicos em suínos. Engenharia Agrícola, v.26, n.1, p.11-19. 2006.

SILVA, K.O.; NÄÄS, I.A.; TOLON, Y.B.; CAMPOS, L.S.L.; SALGADO, D.D. Medidas do ambiente acústico em creche de suínos. Revista Brasileira de Engenharia Agrícola e Ambiental, v.11, n.3, p.339-344, 2007.

WATTS, J.M.; STOOKEY, J.M. Vocal Behaviour in Cattle: The Animal's Commentary on Its Biological Processes and Welfare. Applied Animal Behaviour Science, v.67, n.1, p.15-33, 2000.

WISMANS, W.M.G. Identification and registration of animals in the European Union. Computers and Eletronics in Agriculture, v.24, n.2, p.99-108, 1999.

WOUTERS, P.; GEERS, R.; PARDUYNS, G.; GOOSSENS, K.; TRUYEN, B.; GOEDSEELS, V.; VAN DEER STUYFT, E. Image analysis parameters as inputs for automatic environmental temperature control in the piglets houses. Computers and Electronics in Agriculture, v.5, n.2, p.233-246, 1990.

XIN, H. Assessing swine thermal comfort by image analysis of postural behaviors. Journal of Animal Science, v.77, n.1, p.1-9, 1999. Suppl. 2.

Data de recebimento: 10/11/2011

Data de aprovação: 27/04/2012 